\title{
DE WIRI-WIRI, EEN MUZIEK-INSTRUMENT VAN CURAÇAO
}

DOOR

\author{
C. H. DE GOEJE
}

In een lang gezocht boek 1) vond ik iets over een muziekinstrument van Cuba, dat terstond de herinnering opwekte aan een instrument van Curaçao, de wiriwiri. De afbeelding toont een fleskalebas met een reeks inkepingen dwars op de lengteas, en een strijkhoutje; de beschrijving luidt: ,güiro ó calabazo. Este consiste en un güiro seco al que se le han grabado varias ranuras horizontalas y paralelas en su parte ancha, de manera que forma una especie de rayador (por lo que suele llamarse güayo) sobre el cual se passa á compás una varilla de madera dura, mientras se sostiene con la mano izquierda el pedúnculo."

Mr. J. Kunst, hierover geraadpleegd, verschafte mij een foto van een dergelijk instrument, afkomstig van Puerto Rico. Het wordt ook beschreven door SACHS ${ }^{2}$ ), en deze verwijst naar een opstel 3), luidend: „A writer in the Kansas City Star describes an instrument of this class which has seemed to be confined to the West-Indies. It is called the guira, and is made of a gourd varying in size in different instruments. On the inverse curve of the gourd are cut apertures like the $\int$ holes in a violin. On the other side of the gourd opposite the holes is a series of deep scratches. The player balances the gourd in his left hand, holding it lightly, so that none of the resonance may be lost. With the right hand he rapidly rubs this roughened side of the gourd with a two-tined fork. In the hands of a native guira player a wonderful rhythmic

1) Fernando Ortiz, Hampa Afro-Cubana. Los Negros Brujos, Madrid 1905, p. 79.

2) Curt SAchs, Real-Lexicon der Musikinstrumente, Berlin 1913, $.167 b$.

3) E. H. Hawley, The notched rattle; The American Anthropologist XI, Washington 1898 , p. 344 . 
sound comes from this dried vegetable shell, a sound which in its place in the orchestra, becomes music, and most certainly gives splendid time and considerable volume to the performance. The player's hand moves with lightning rapidity. The steel fork at times makes long sweeps, the whole length of the gourd, and then again vibrates with incredible swiftness over only an inch or two of its surface."

Toen ik mij tot een Curaçaose dame wendde, om nog eens precies te vernemen hoe de wiri-wiri bespeeld wordt, wees deze mij op een onlangs verschenen boek en gaf het mij ter inzage. Dit vermeldt 1 ):

„Wiri". Van alle beschreven instrumenten, heeft op Curaçao alleen de ,,wiri" in den loop der tijden groote veranderingen ondergaan. In den ouden tijd werd zij gemaakt van een gedroogde en uitgeholde ,kalbas largoe” (lange kalebas), waarover, terwijl de vrucht nog niet heelemaal droog, dus nog zacht was, met een scherp mes in dwarsrichting ribben waren ingekorven. In den loop der tijden moest dit materiaal plaats maken voor den koehoorn, waarover met een vijl eveneens ribben waren gegroefd. Op zijn beurt moest later ook de koehoorn wijken voor staal. Was het instrument uit een kalebas of koehoorn gemaakt, dan werd aan den onderkant een gat geboord, waardoor de bespeler zijn linkerduim stak om het instrument stevig te kunnen vasthouden, terwijl de bespeling plaats vond door middel van een scherp geslepen stuk been, hoorn of metaal. Het bracht een ritselend geluid voort, niet zoo scherp als bij de latere wiri's, die echter nooit door het volk bij zijn feesten en danspartijen werden gebruikt, doch vervaardigd werden ter begeleiding van de zoogenaamde Italiaansche draaiorgels, toen deze hun intree hadden gedaan op ons eiland tusschen 1880-1890.

Het geluid door den koehoorn of kalebas voortgebracht, was niet sterk genoeg en werd overstemd door het geluid van het orgel, dat in feite met een orgel slechts den naam gemeen had, maar veel beter mechanische of draaipiano kon worden genoemd.

Hiermede zijn alle instrumenten beschreven, die sinds den ouden tijd bij het Curaçaosche volk in gebruik waren en de veranderingen, die zij op Curaçaoschen bodem hebben ondergaan. Dat ze allemaal, met uitzondering van den kinkhoorn, van Afrikaanschen oorsprong waren, is aan geen twijfel onderhevig. Alle

1) N. van Meeteren, Volkskunde van Curaçao, Willemstad 1947, p. $42-43$. 
equivalenten met kleine afwijkingen, maar ook zonder afwijkingen, worden nog heden ten dage in Afrika, in de streken om den evenaar, en soms ook verder aangetroffen."

De Encyclopaedie van Nederlandsch West-Indië 1) vergelijkt de wiri-wiri met een instrument van het Surinaams orkest: twee stukken ijzer, die de muzikant tegen elkaar slaat (,isri nanga isri", ijzer met ijzer $\left.{ }^{2}\right)$ ). Doch vermoedelijk ten onrechte, want VAN MEETEREN beschrijft in zijn verdienstelijk werk (p. 40) een dergelijk instrument van Curaçao als volgt: „Agan”. Ook „heroe" genaamd. Twee stukken staal, zonder bepaalden vorm of grootte, meestal afkomstig van een ouden ploeg, die tegen elkaar werden geslagen en maat en tempo aangaven aan de andere instrumenten. Bij den tamboerdans, waarover later, werd de trom steeds door de ,,agan" begeleid en nooit door de ,,wiri”. Dit instrument kon eenigszins vergeleken worden met den triangel in onze orkesten." Hij noemt ook een dergelijk instrument van Haïti, daar ,ogan” genoemd en zegt: „Het staat vast, dat de „Agan” uit Afrika stamt”. Een triangel komt ook voor bij Negers in Brazilië 3).

Zonder twijfel schuilen er in de cultuur der Amerikaanse Negers veel elementen die de voorouders uit Afrika hebben medegenomen, en in Afrika waren schraapinstrumenten in gebruik. Doch ook in Oost-Azië tot en met Java had men schraap- (of rasp-)instrumenten 4), en bovendien in het oude Mexico ${ }^{5}$ ), en er zijn aanwijzingen dat er vroeger aanrakingen zijn geweest tussen bewoners van Midden-Amerika en de bevolking der Antillen.

De naam zegt ons weinig. In de Spaanse taal van Cuba beduidt guira kalebas; het woord is bekend uit de taal van de bewoners der Grote Antillen ten tijde der ontdekking, uit de vrouwentaal der Kleine Antillen en uit het Arawaks en andere verwante talen, en beduidt $i w i$ vrucht $e d a$ schaal 6). Gesteld dat wiri-wiri denzelf-

1) 's-Gravenhage/Leiden 1914-1917, p. 498.

2) M. J. and F. S. Herskovitz, Suriname Folk Lore, New York 1937, p. 87.

3) L. Gallet, Estudios de folclore, Rio de Janeiro 1934, p. 59 (aangehaald door A. Ramos, O Negro Brasileiro, Rio de Janeiro 1934, p. 165).

4) J. Kunst, Een onbekend Javaansch muziekinstrument, Cultureel Indië, I, Leiden 1839 , p. $140-3$.

s) E. Seler, Gesammelte Abhandlungen zur Amerikanischen Sprachund Altertumskunde II. Band, Berlin 1904, pp. 672, 695.

6) C. H. DE Goeje, Nouvel examen des langues des Antilles, J. Soc. Amér. XXXI, 1939, p. 25. 
den oorsprong heeft, dan is het toch nog onzeker of dit een overblijfsel is uit de taal der Bewoners van Curaçao ten tijde der ontdekking of dat het medegebracht is door later derwaarts overgebrachte Indianen of Negers, of met het Spaans is medegekomen.

De vraag naar den oorsprong wordt nog moeilijker, doordien, zoals Mr. KUNST opmerkte, schraapinstrumenten gemakkelijk op verschillende plaatsen, onafhankelijk van elkaar kunnen zijn uitgevonden. De op de kalebas van Puerto Rico ingekraste tekening doet echter zéér denken aan een Indiaans patroon. En een nog belangrijker aanwijzing geeft ons het ,Schriftuur van Broeder Roman (Ramon Pane) over de oudheid der Indianen, dat deze met zorgvuldigheid, als man die hun taal kent, opgesteld heeft op last van den admiraal (Columbus)" 1). Dit geschrift heeft betrekking op de Indianen van Haïti in hun nog vrijwel ongerepten staat; o.m. vermeldt het: ,Als deze lieden hun heilige overleveringen zingen, bespelen zij daarbij een zeker instrument dat men maiohaua noemt, dat van hout is en hol, sterk en fijn, lang één en breed een halve el (d.i. ongeveer $60 \times 30 \mathrm{~cm}$ ); het gedeelte waar (waarmede) men speelt is gemaakt in den vorm van de tang van een hoefsmid, en aan de andere zijde lijkt het op een knots; op de wijze van een kalebas met langen hals; en dit instrumen bespeelt men, en het klinkt zo luid, dat men het anderhalve mijl ver hoort; en bij dezen klank zingen zij hun liederen, die ze in hun geest prenten; en de voornaamste mannen bespelen dit, welke van jongsaf leren het te laten klinken en daarbij te zingen, volgens hun zede".

Men heeft gemeend dat deze beschrijving betrekking had op een Indiaansen rammelaar 2), doch thans wordt het wel zeer waarschijnlijk dat het een soortgelijk instrument was als de guira en de oude wiriwiri. Dan zou dus de wiriwiri van Curaçao een echt West-Indisch Instrument zijn, afkomstig van de vroegere, Indiaanse, bevolking der eilanden.

1) Raccolta di documenti e studi publicata dalla R. Commissione Colombiana, Parte I Volume I, Roma 1892 p. 217.

2) Sven Lovén, Origins of the Tainan culture, West-Indies, Göteborg, 1935 p. 492; de Goeje, op. cit. p. 7. Volgens Ortiz heet de Cubaanse rammelaar marugo, wat kennelijk het Indiaanse woord maraka is. 